Article

\title{
Understanding the Effects of Climate Change on Urban Stormwater Infrastructures in the Las Vegas Valley
}

\author{
Ranjeet Thakali ${ }^{1}$, Ajay Kalra ${ }^{1, *}$ and Sajjad Ahmad ${ }^{2}$ \\ 1 Department of Civil and Environmental Engineering, Southern Illinois University, 1230 Lincoln Drive, \\ Carbondale, IL 62901, USA; ranjeet@siu.edu \\ 2 Department of Civil and Environmental Engineering and Construction, University of Nevada, \\ 4505 S. Maryland Parkway, Las Vegas, NV 89154, USA; sajjad.ahmad@unlv.edu \\ * Correspondence: kalraa@siu.edu; Tel.: +1-618-453-7008
}

Academic Editor: Luca Brocca

Received: 5 June 2016; Accepted: 18 October 2016; Published: 26 October 2016

\begin{abstract}
The intensification of the hydrological cycle due to climate change entails more frequent and intense rainfall. As a result, urban water systems will be disproportionately affected by the climate change, especially in such urban areas as Las Vegas, which concentrates its population, infrastructure, and economic activity. Proper design and management of stormwater facilities are needed to attenuate the severe effects of extreme rainfall events. The North American Regional Climate Change Assessment Program is developing multiple high-resolution projected-climate data from different combinations of regional climate models and global climate models. The objective of this study was to evaluate existing stormwater facilities of a watershed within the Las Vegas Valley in southern Nevada by using a robust design method for the projected climate. The projected climate change was incorporated into the model at the 100 year return period with $6 \mathrm{~h}$ duration depths, using a statistical regionalization analysis method. Projection from different sets of climate model combinations varied substantially. Gridded reanalysis data were used to assess the performance of the climate models. An existing Hydrologic Engineering Center's Hydrological Modeling System (HEC-HMS) model was implemented using the projected change in standard design storm. Hydrological simulation using HEC-HMS showed exceedances of existing stormwater facilities that were designed under the assumption of stationarity design depth. Recognizing climate change and taking an immediate approach in assessing the city's vulnerability by using proper strategic planning would benefit the urban sector and improve the quality of life.
\end{abstract}

Keywords: climate change; urban stormwater; Flamingo and Tropicana watershed; HEC-HMS

\section{Introduction}

Climate change has several direct influences that contribute to altering the intensity, frequency, amount, and type of precipitation [1]. Recent studies on climate change suggest a significant rise in the severity of extreme weather events over the next century [2-5]. In particular, intensified precipitation is expected to occur more frequently, leading to severe hydrologic consequences, such as a greater amount of flooding and erosion [6,7]. In the analysis of recorded rainfall time series in many regions, heavy rainfall events have indicated an increasing trend $[8,9]$. Studies on climate change provide evidence that even in regions of decreasing total-rainfall trends, the intensity of the extreme-rainfall events may increase [10]. In addition, there is a $90 \%$ probability of increasing extreme rainfall events throughout the 21st century [1]. 
United States has grown as a progressively urban society since last century [11]. Urbanization augments the impervious areas, resulting in less infiltration of rainwater and, consequently, magnified hydrologic effects [12]. The change in land cover associated with urbanization has resulted in an increase in discharge, volume, and frequency of floods [11]. Future changes in high-intensity rainfalls that are derived from climate change will have amplified effects on urban stormwater systems.

Stormwater infrastructures are used to convey water from storm runoff to outlets, and serve as artificial flood-mitigation facilities. The proper design and management of stormwater drainage systems can attenuate the more severe effects of extreme rainfall events. The current prevailing standards for the design of stormwater drainage systems are based on the assumption that the probability distribution of rainfall extremes remains statistically stationary $[13,14]$. The climate change has resulted in uncertainty regarding the future performance of facilities designed and built under this standard [15]. A nonstationary nature of the recent extreme events has directed researchers for the need of better flood protection practice [14]. The increased frequency and magnitude of storm events could surpass the capacity of stormwater facilities and increase the amount of total sediment transport [16]. The effects of excess rainfall range from the localized street to large-scale flooding.

Increasing uncertainty resulting from the fast-changing nature of climate is becoming a major challenge in the field of water management [17-19]. The current practice for hydrologic design of stormwater facilities uses precipitation depths calculated from the analysis of historical data for a standard return period [16]. Design from the analysis of historical data does not account for the effects of climate change on future meteorological conditions. Thus, the assumption may be subjected to errors [20]. The conventional method of stationarity-based design of water management systems has long been compromising the fluctuating nature of climate [21]. Predicted changes in climate over the next century necessitates a change in the current traditional practices for stormwater facilities design [22]. More flexible and robust design methods are needed to incorporate climate-induced changes $[16,20]$. These methods should be simple and straightforward enough in their application for design engineers and water managers. In the current urban drainage design practice, the use of the hydrological models such as design, planning, and management have become common practice. New design practices need to include the use of existing hydrological models for different places with some necessary adjustments [23]. Surface hydrology models are used to study and design stormwater facilities, especially to assess the effects of climate change [24]. These models take rainfall input as event-based data or continuous time-series data.

Various types of climate models are used to assess the effects of climate change. Projected climate data from global climate models (GCMs) and regional climate models (RCMs) are found in gridded datasets. RCMs are used to downscale coarsely gridded data from GCMs to the regional level $[2,25]$. These climate models assess climate change scenarios with different assumptions, and the output varies substantially in each. Assessment of climate-change effects on future hydrologic conditions should take into consideration various climate models in order to account for the inherent uncertainty of projected outputs [25]. The North American Regional Climate Change Assessment Program (NARCCAP) provides various sets of climate data using the nesting technique between the synoptic-scale GCMs and the associated mesoscale spatial and temporal resolution fields simulated by RCMs [26]. Both GCMs and RCMs project the effects of climate change on hydrology; however, the level of detail for both models is not suitable for hydrological application [7]. Projected data from these climate models are contingent on systematic bias, particularly with regard to precipitation [27]. Generally, two types of downscaling methods, statistical downscaling and dynamical downscaling, are used to link the projected climate outputs to the desired catchment-level hydrological application of climate-change effects $[25,28]$. These downscaling methods are not straightforward to apply. The delta change method (DCM), which serves as an alternative to more complicated downscaling methods, transposes the gridded future climate data to point-precipitation data $[29,30]$. DCMs include pertinent information for assessing hydrological effects induced by climate change; its implementation is simple and straightforward [29]. In DCM, calculated deviations between the gridded projected future and 
historic precipitation are converted to the point-historic precipitation. In the analysis of future extreme rainfall, areal reduction factors are assumed to be the same for a given region, duration, and return period [30].

The use of the hydrological models for the analysis or design of urban stormwater infrastructure is becoming a common practice. Better understanding of the hydrologic processes and improvement in computational speed have increased the usefulness of hydrological computer models. There are dozens of models available in the market, which are developed by government departments, regulatory authorities, engineering consultants, and academic institutions [31]. The selection of a model depends on complexity, available resources, and modeling objectives [32]. The extensive review with appropriate applicable areas of the available hydrological models are well documented in the studies such as Zoppou [31], Elliott and Trowsdale [33], and Salvadore et al. [34].

Previous studies on climate change, Mailhot and Duchesne [20], Wernstedt and Carlet [22], Mailhot et al. [30], Grum et al. [35], He et al. [36], and Brown [37] have suggested the replacement of the current design standard by a simple and robust method that includes the effects of climate change. However, these studies are limited for the following reasons. First, the performance of stormwater systems under a combination of urbanization and climate change have not been well assessed by previous studies. Second, previous studies do not suggest any specific and well-defined method that accounts for climate change.

The main scope of this study is to depict the potential effects of climate change on existing infrastructure systems for urban stormwater, using the robust design method. Historical and projected future precipitation from all the available GCM-driven and RCM-projected precipitation data from NARCCAP were employed to calculate the deviation between historical and future design storm. The data that best represents the historical precipitation were used to calculate the delta-change factors, and were applied to the design storm depths. Using these delta-change factors, the stormwater systems were analyzed for various scenarios in an existing Hydrologic Engineering Center's Hydrological Modeling System (HEC-HMS) model of Las Vegas Valley watershed developed by the Clark County Regional Flood Control District (CCRFCD). The subsequent sections of this paper provide details about the study area, data, models, and methodologies used for the analysis, followed by the findings and conclusions of this research.

\section{Study Area}

The southwest region is the most arid and hottest area of United States, and the natural climate variability affects many aspects of life, decision-making, livelihoods, and landscape. Currently, the southwest region is experiencing extreme rainfall and consequent flooding from natural fluctuation; this region could be considered as one of the most climate-challenged areas of North America [38]. In arid areas, the flood hydrograph of the ephemeral basins has steep-rising limbs [39]. Managing stormwater systems in an arid-urbanized area with respect to the changing-climate scenario is not an easy task.

The Las Vegas Valley is spread over approximately $1600 \mathrm{~km}^{2}$ of southern Nevada in the United States. The arid, northwest-trending valley is surrounded by several mountain ranges on the west, and drains southeastward by way of the Las Vegas Wash into Lake Mead. Over the last 20 years, the Las Vegas Valley has experienced several severe storms that have exceeded the standard value of 100 year return period with $6 \mathrm{~h}$ duration design runoff. Among these storms, those that occurred on July 1975, July 1999, August 2003, January 2005, and September 2012 were the most devastating, affecting many public and private infrastructures [40,41]. According to the flood reports from the CCRFCD, Las Vegas has been experiencing highly convective and intense rainfall every year over the last couple of decades. The Flamingo and Tropicana watershed (Figure 1), one of the major watersheds within the Las Vegas Valley, was chosen for this study.

The urbanized Flamingo and Tropicana watershed covers the southwest and central portions of the valley, and extends from $35.95^{\circ} \mathrm{N}$ to $36.22^{\circ} \mathrm{N}$ latitudes and $115.04^{\circ} \mathrm{W}$ to $115.53^{\circ} \mathrm{W}$ longitudes. 
The boundaries of the watershed extend over an area of approximately $570 \mathrm{~km}^{2}$. The average annual precipitation of Las Vegas is $10.64 \mathrm{~cm}$, which is evenly divided between the summer and winter rainy seasons [42]. The detention basins, which are linked by conveyance facilities, are the principal medium of drainage within the watershed.

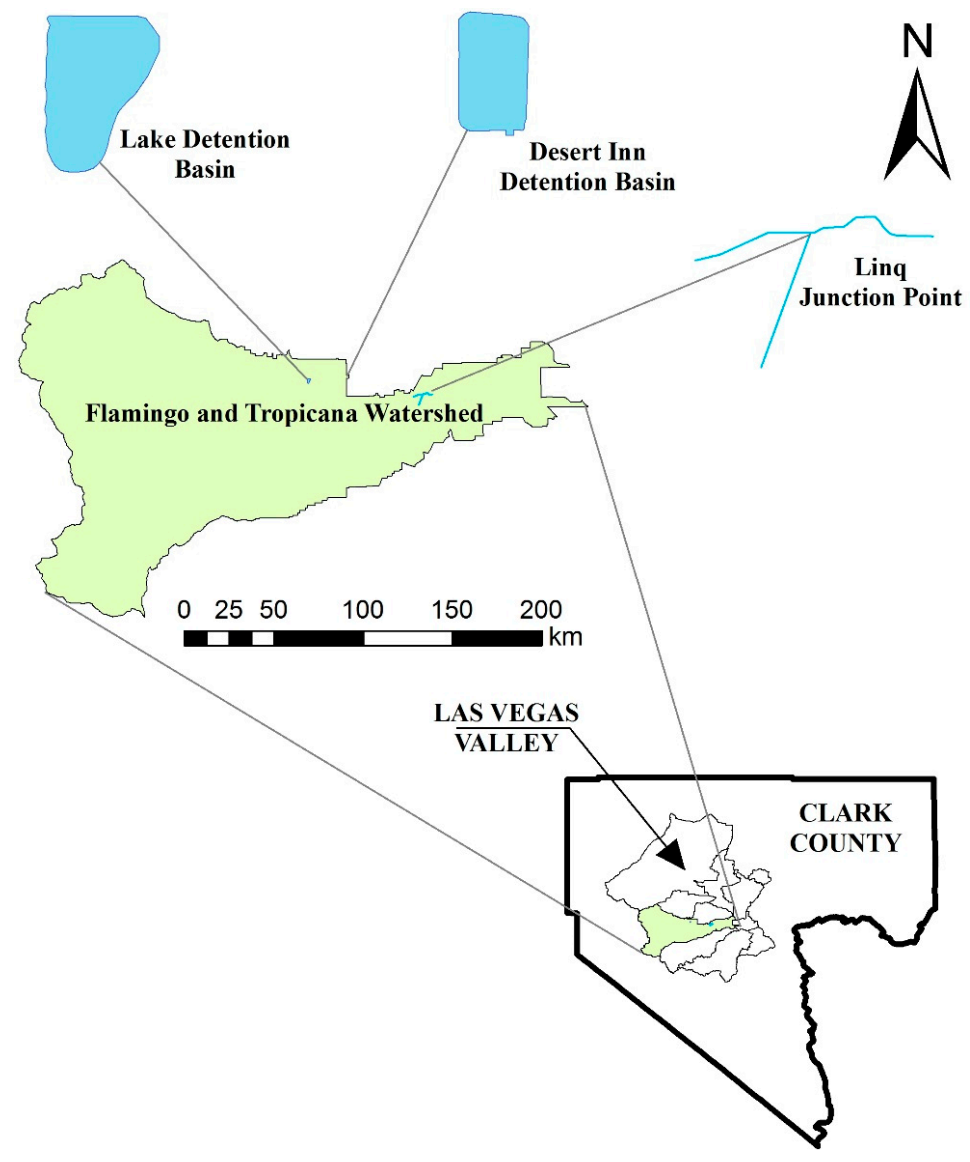

Figure 1. Map depicting the Flamingo and Tropicana watershed within the Las Vegas Valley, Nevada, along with the key drainage infrastructures that were analyzed for this study.

\section{Data and Model}

GCM-driven RCM-projected climatic datasets of NARCCAP were used to project precipitation depths for the Flamingo and Tropicana watershed. NARCCAP provides the potential future climate scenarios over the United States, Canada, and Northern Mexico [43]. The sets of NARCCAP data used in this study are tabulated in Table 1.

The principal scientific goal of the NARCCAP project is to develop multiple high-resolution regional climate scenarios from GCMs and RCMs [43]. Two major phases are included to project the NARCCAP data:

1 In the first phase, six RCM boundary conditions for a 25 year period (1979-2004) were used based on the data from the Atmospheric Model Intercomparison Project (AMIP-II) Reanalysis, conducted by the National Centers for Environmental Prediction and the U.S. Department of Energy (NCEP/DOE).

2 In the second phase, four GCMs having time spans 30 years each for both historical climate data (1971-2000) and future climate data (2041-2070) were used for boundary conditions, taking into consideration the A2 scenarios from the Special Report on Emissions Scenarios (SRES) by the Intergovernmental Panel on Climate Change (IPCC) [44]. 
Table 1. Combination of global climate models (GCMs) and regional climate models (RCMs) in the NARCCAP climate models adopted for this study.

\begin{tabular}{cll}
\hline $\begin{array}{c}\text { Model Combination } \\
\text { (GCM/RCM) }\end{array}$ & \multicolumn{1}{c}{ GCM } & \multicolumn{1}{c}{ RCM } \\
\hline CGCM3/CRCM & Third Generation Coupled Global Climate Model & Canadian Regional Climate Model \\
CGCM3/RCM3 & Third Generation Coupled Global Climate Model & Regional Climate Model version 3 \\
CGCM3/WRFG & Third Generation Coupled Global Climate Model & Weather Research and Forecasting Model \\
CCSM/CRCM & Community Climate System Model & Canadian Regional Climate Model \\
CCSM/WRFG & Community Climate System Model & Weather Research and Forecasting Model \\
CCSM/MM5I & Community Climate System Model & MM5, the PSU/NCAR Mesoscale Model \\
HaDCM3/HRM3 & Hadley Centre Coupled Global Climate Model & Hadley Regional model 3 \\
HaDCM3/MM5I & Hadley Centre Coupled Global Climate Model & MM5-PSU/NCAR Mesoscale Model \\
GFDL/HRM3 & Geophysical Fluid Dynamics Laboratory & Hadley Regional model 3 \\
GFDL/RCM3 & Geophysical Fluid Dynamics Laboratory & Regional Climate Model version 3 \\
GFDL/ECPC & Geophysical Fluid Dynamics Laboratory & Experimental Climate Prediction Center \\
Time slice GFDL & Geophysical Fluid Dynamics Laboratory & \\
Time slice CCSM & Community Climate System Model & \\
\hline
\end{tabular}

As of 2016, 11 sets of NARCCAP current and future climate were produced along with two time slices for the Community Atmosphere Model, version 3, of the National Center for Atmospheric Research (NCAR GCM, CAM3) and the atmospheric model (AM2.1) of the Geophysical Fluid Dynamics Laboratory (GFDL) [28]. All the NARCCAP datasets give 3-hourly temporal resolutions at the $50 \mathrm{~km}$ horizontal grid spacing climate change scenario.

The model-simulated output from historic NARCCAP data was assessed by another high-resolution historic hydrology dataset, North American Regional Reanalysis (NARR) [45]. NARR data is an extensive work of the National Centers for Environmental Prediction (NCEP) towards the major improvement upon earlier NCEP/NCAR Global Reanalysis [46]. The reanalyses use observation and model output to produce a long-term systematic description of the climate system; the output data are considered as gridded estimations of historic observations [46]. The resolution of NARR (32 $\mathrm{km}$ resolution), is smaller than the NARCCAP data resolution. Unlike the NARCCAP data, the NARR data are available from 1979 to 2015 . However, both have the same $3 \mathrm{~h}$ temporal resolution. Since the NARCCAP data do not have a historic dataset after 2000, this study only considers the NARR data from 1979 to 2000.

Since 1985, the CCRFCD has been developing a coordinated and comprehensive master plan for the Las Vegas Valley to handle the possible flooding scenarios. The master plan, issued in 1991 for the Las Vegas Valley, is updated every five years to take account the changing scenarios over time. As part of updating CCRFCD's master plan, the valley is divided into 11 watersheds, and is modeled in the USACE's HEC [47]. The HEC-HMS allows simulation of channel behavior as well as water-control structures for the watershed, thus predicting the hydrological parameters, flow, stages, and timing. Each master plan update (MPU) uses an ultimate development boundary, which represents the future land-use data of full build-out conditions [47]. Changes in the ultimate hydrologic conditions of the Flamingo and Tropicana watershed after the amendment of CCRFCD's MPU 2008 were considered minor, and remained the same in the latest MPU 2013. This study uses the same 2008 HEC-HMS model.

The design and development of all the drainage facilities within the CCRFCD follow the guidelines from the Hydrologic Criteria and Drainage Design Manual [48]. The precipitation depths estimated by the National Oceanic and Atmospheric Administration (NOAA) Atlas II for a 100 year event with duration of $6 \mathrm{~h}(100 \mathrm{yr}-6 \mathrm{hr})$, multiplied by an adjustment factor of 1.43, were assigned to each sub-basin in the HEC-HMS model $[49,50]$. This adjusted precipitation depth varies from a $7.04 \mathrm{~cm}$ minimum to a $10.62 \mathrm{~cm}$ maximum for the Flamingo and Tropicana watershed. These precipitation depths represent rainfall frequency at isolated points; however, storms occur over a widespread area and do not produce the uniform precipitation over the entire watershed. The depth-area reduction factor (DARF) is used to account the variation in rainfall. HEC-HMS uses a single DARF. In this study, the CCRFCD design manual was used to calculate the DARF. The basic principle in calculating DARF is that the average 
precipitation intensity decreases with an increase in the area of a storm. The Flamingo and Tropicana watershed was further divided into 328 sub-basins in the model. This model included the various basin models, and each of these models considered various conditions of storm centering.

\section{Methodology}

A series of multiple methods were adopted for this study. First, the regional frequency analysis (RFA) based on L-moments (a linear combination of probability-weighted moments) was used to calculate the design storm depth (i.e., $100 \mathrm{yr}$-6hr) from the all the datasets of NARCCAP and NARR. To screen the data, historical design depths of NARCCAP were assessed using NARR depths. The existing HEC-HMS model of the Flamingo and Tropicana watershed was enacted to assess the effects of climate change on stormwater facilities. The output from HEC-HMS was analyzed further according to guidelines from the CCRFCD design manual, and comparisons were made among the various climate projection scenarios.

The climate model provides gridded information of definite spatial resolution. The size of the data can be increased for better analyses by using data from the area of interest as well as nearby homogeneous grid data. RFA serves as a transformation tool, and is the most appropriate technique in studies using climate models. Calculation of the design storm depth from the dataset of homogeneous sites by the RFA using the L-moment is more reliable than a single-site analysis [51]. The sole use of the data from a single grid of area of study has several shortcomings, which were discussed in some recent studies [52]. RFA has been used for a long time to calculate flood frequency analyses such as Burn [53], Castellarin et al. [54], and Norbiato et al. [55]. However, it has not been used as much for the study of climate model data [56].

Data from four encompassing grids of the Flamingo and Tropicana watershed were used for the RFA. First, the $3 \mathrm{~h}$ NARCCAP precipitation data were aggregated to $6 \mathrm{~h}$ precipitation data by shifting a $6 \mathrm{~h}$ window through each $3 \mathrm{~h}$ value. Using an algorithm, the series of $6 \mathrm{~h}$ annual maximum data were calculated for each grid and model combinations. For regionalization, the data were pooled by dividing each maximum by a median of the same data series for each grid [56]. The RFA method mentioned in the Flood Estimation Handbook by the Institute of Hydrology, U.K., [57] for forecasting streamflow was followed in this study.

The generalized extreme value (GEV) distribution was fitted to each standardized polled-annual extreme dataset of all the four grids of each climate-model combination. In the precipitation frequency atlas of NOAA, various statistical distributions were examined for the best-representative distribution of meteorological conditions for different homogeneous climate divisions [58]. Bonnin et al. [58] found that the GEV probability distribution produced the best fit for the Clark County region. Other studies, such as Kharin and Zwiers [59] and Mailhot et al. [30], also used the GEV distribution method to calculate extreme-rainfall storms by using climate model datasets. The GEV distribution method is a commonly accepted approach in the nonstationarity study of extreme flows owing to the skewed nature of annual flow maxima and the ability to include covariates in the parameters of distribution [60-64]. The shape, location, and scale parameters required to fit the GEV distribution to each standardized pool of data were estimated using L-moments [51]. Using these parameters, 100yr-6hr design depths were calculated. Further, the median of the grid, which encloses the centroid of the Flamingo and Tropicana, was used to rescale the standardized 100yr-6hr depth. This process was performed for all sets of the data from each climate model. Finally, the delta-change factors were calculated by dividing the projected future $100 \mathrm{yr}-6 \mathrm{hr}$ depth by historic $100 \mathrm{yr}-6 \mathrm{hr}$ depths.

The same statistical method was used to calculate the 100yr-6hr depth from the NARR historic dataset. The calculated $100 \mathrm{yr}-6 \mathrm{hr}$ was used to assess the performance of the NARCCAP datasets. The depth determined by the area average decreases with an increase in total area. Thus, the depths calculated from a $50 \mathrm{~km}$ resolution NARCCAP depth must be less than those from a $32 \mathrm{~km}$ resolution NARR depth. Once finding the best representative historic rainfall reproduced by the NARCCAP model, the stormwater infrastructures were evaluated using HEC-HMS under the projected 
climate-change conditions. To account for the consequences of climate change, the existing HEC-HMS model was run with no changes. To assess the effects of climate change, the delta change factor (DCF) calculated from the NARCCAP models were used for all existing design depths of the HEC-HMS model. In the HEC-HMS model analysis, stormwater facilities were used to simulate flow conditions by using a baseline scenario as well as climate change scenarios. No model parameters were changed from the existing HEC-HMS in the baseline scenario. The two extreme DCFs were used to account for the climate change scenarios.

For hydrological analysis, two detention basins were selected, Lakes Detention Basin (LAKEDB) and the Desert Inn Detention Basin (DIDB), as well as a drainage junction point (JP) near the Linq Hotel parking area where frequent flooding has been reported in recent years. The flooding issues of this area are archived in many journals; some of the news about a recent flooding that happened on 9 April 2016 is covered in the online journals [65,66]. An overview of the selected stormwater components is shown in Figure 1. The simulation period was set to $24 \mathrm{~h}$, starting from 1:05 am, and the computational control period was five minutes. To determine the greatest maximum hydrological parameters, the analysis was conducted using two different basin models: a base model, with storm centering over the entire Flamingo and Tropicana watershed, and a storm-centering (SC) model, with storm centering for the Flamingo and Tropicana Wash confluence.

\section{Results}

The 100yr-6hr design depths were calculated from 13 NARCCAP sets (11 RCM and GCM combinations and two time slices), along with the NARR 100yr-6hr historical depths, which are tabulated in Table 2. A comparison of calculated design depths (historical and future) are shown in Figure 2. In Figure 2, 100yr-6hr historic depths are plotted on the x-axis, and 100yr-6hr future depths are plotted on the y-axis, in centimeters. The vertical line denotes the calculated NARR historic $100 \mathrm{yr}-6 \mathrm{hr}$ depth.

The historical depths from six NARCCAP models (CGCM3/CRCM, CGCM3/WRFG, CCSM/CRCM, HaDCM3/ HRM3, Time slice GFDL, and Time slice CCSM) listed below, were less than that of NARR historical depth, and are depicted on the left side of the vertical line of Figure 2. On the other hand, 100yr-6hr historic depths calculated from seven NARCCAP datasets (CGCM3/RCM3, GFDL/RCM3, CCSM/MM5I, HaDCM3/MM5I, GFDL/HRM3, CCSM/WRFG, and GFDL/ECPC) were greater than the NARR historic depths and are shown in right side of the vertical line of Figure 2.

Table 2. Historic and projected 100yr-6hr depths and delta change factors from North American Regional Climate Change Assessment Program (NARCCAP) and North American Regional Reanalysis (NARR) climate models.

\begin{tabular}{|c|c|c|c|}
\hline $\begin{array}{l}\text { Model Combination } \\
\text { GCM/RCM }\end{array}$ & $\begin{array}{l}\text { Historic 100yr-6hr Depth } \\
(\mathrm{cm})\end{array}$ & $\begin{array}{l}\text { Future 100yr-6hr Depth } \\
(\mathrm{cm})\end{array}$ & Delta Change Factor \\
\hline NARR & 2.98 & - & - \\
\hline CGCM3/CRCM & 1.57 & 2.40 & 1.53 \\
\hline CGCM3/RCM3 & 3.84 & 3.42 & 0.89 \\
\hline CGCM3/WRFG & 2.72 & 3.74 & 1.37 \\
\hline CCSM/CRCM & 2.05 & 2.30 & 1.12 \\
\hline CCSM/WRFG & 3.70 & 3.92 & 1.06 \\
\hline CCSM/MM5I & 3.55 & 4.17 & 1.17 \\
\hline HaDCM3/HRM3 & 2.93 & 5.45 & 1.86 \\
\hline HaDCM3/MM5I & 4.14 & 5.52 & 1.33 \\
\hline GFDL/HRM3 & 8.55 & 8.86 & 1.04 \\
\hline GFDL/RCM3 & 5.34 & 5.93 & 1.11 \\
\hline GFDL/ECPC & 6.03 & 7.87 & 1.30 \\
\hline Time slice GFDL & 2.74 & 3.94 & 1.44 \\
\hline Time slice CCSM & 2.41 & 2.52 & 1.05 \\
\hline
\end{tabular}




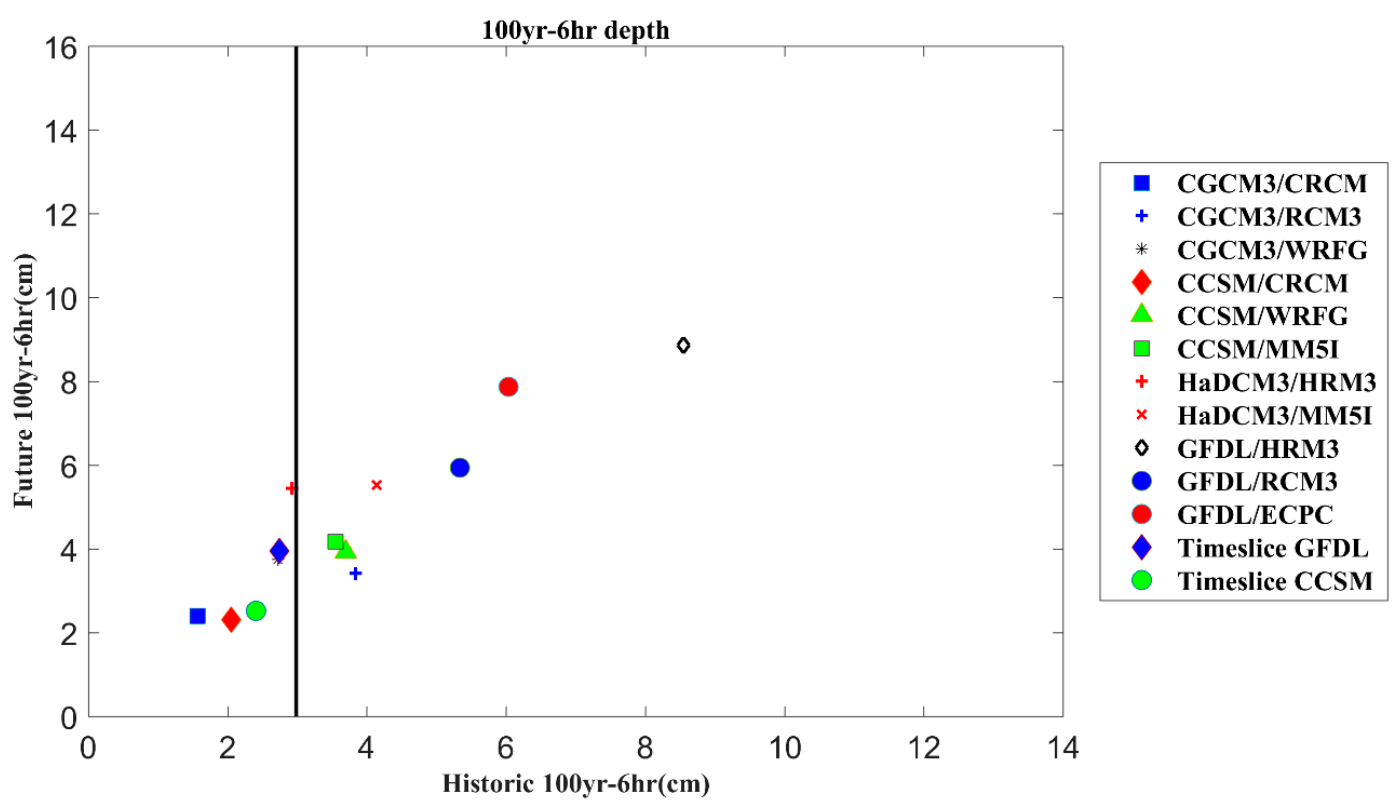

Figure 2. Historic vs future depths (100yr-6hr) of the NARCCAP climate models. The vertical line represents the NARR historical 100yr-6hr depth.

The DCF ratio of future and historic 100yr-6hr depths from all the model combinations are shown in Table 2. The DCF from all the datasets are plotted in Figure 3, where the horizontal line (no-change line) represents no changes in the climate scenario (i.e., DCF $=1$ ); the points below the line are negative delta-change factors. Similarly, the points above the no-change line indicate positive delta-change factors.

One NARCCAP climate model-CGCM3/RCM3 - showed a negative delta-change factor but this model was eliminated during the assessment with NARR design depth. Among the six selected DCFs, the smallest (1.05) and largest (1.86) were taken for further hydrologic analyses. They were labeled as Climate Change Scenario 1.05 (CCS 1.05) and Climate Change Scenario 1.86 (CCS 1.86), respectively, for the smallest and largest DCFs.

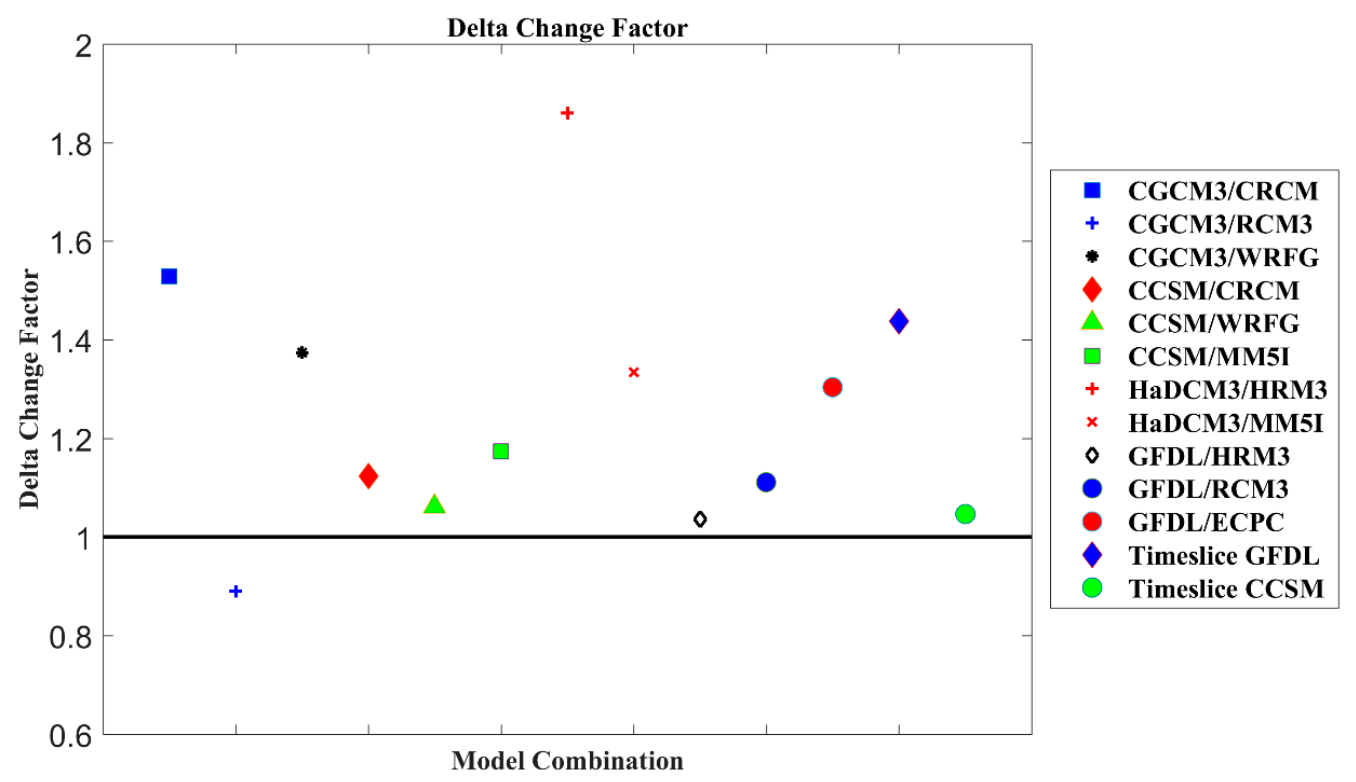

Figure 3. Delta change factor for all the NARCAAP datasets. The horizontal line represents the "no changes in future" climate scenario $(\mathrm{DCF}=1)$. 
Results from the HEC-HMS flow simulations (base model and SC) were used to compare its outputs, discharge, elevation, inflow, and storage. For the baseline-scenario analysis, a base model with DARFs of 0.925 and 0.95 were used for LAKEDB and DIDB, respectively. The total drainage areas for LAKEDB and DIDB were 6.78 and $2.67 \mathrm{~km}^{2}$, respectively, which govern the DARF value [48]. Similarly, an SC basin with a DARF of 0.908 was used for the baseline scenario analysis of JP. For all three elements, along with the model from the baseline scenarios, an SC basin with a DARF of 0.875 was used to determine the maximum values of modeling outputs, using two climate change scenarios.

Outputs from the HEC-HMS models, the base model, and SC are shown in Table 3. The inflow, discharge, and elevation were the direct maximum values from the HEC-HMS model. However, to calculate a change in elevation, the elevation value corresponding to zero inflow was taken as the datum elevation. The output values-discharge, elevation, and inflow-were compared against the design values from CCRFCD 100yr-6hr design rainfall.

Table 3. Hydrological simulation outputs for the Lake Detention Basin (LAKEDB), Desert Inn Detention Basin (DIDB), and the junction point (JP) near the Linq Hotel parking area.

\begin{tabular}{cccccc}
\hline Element & Scenario & Inflow $\left(\mathbf{m}^{\mathbf{3}} / \mathbf{s}\right)$ & Storage $\left.\mathbf{( m}^{\mathbf{3}}\right)$ & Change in Elevation $(\mathbf{m})$ & Outflow $\left(\mathbf{m}^{\mathbf{3}} / \mathbf{s}\right)$ \\
\hline \multirow{5}{*}{ LAKEDB } & Design & 55.95 & $203,524.20$ & 7.83 & 2.72 \\
& Baseline & 55.73 & $203,770.90$ & 7.83 & 2.45 \\
& CCS 1.05 & 60.26 & $221,162.96$ & 10.67 & 2.73 \\
& CCS 1.86 & 135.71 & $504,863.36$ & 79.10 & 9.25 \\
\hline \multirow{5}{*}{ DIDB } & Design & 21.07 & $76,475.76$ & 3.26 & 0.82 \\
& Baseline & 20.93 & $73,392.06$ & 3.26 & 0.82 \\
& CCS 1.05 & 22.66 & $79,806.16$ & 4.30 & 0.92 \\
& CCS 1.86 & 52.20 & $185,268.70$ & 30.36 & 3.35 \\
\hline \multirow{5}{*}{ DIDB } & Design & 76.17 & - & - & - \\
& Baseline & 75.71 & - & - & - \\
& CCS 1.05 & 80.25 & - & - & - \\
\hline
\end{tabular}

Storage values, shown in Table 3, were for storage at the spillway and not for 100yr-6hr design storm. Maximum hydrological parameters were estimated with various DARFs. For analysis of the baseline scenario, base models with DARFs of 0.925 and 0.95 were used for LAKEDB and DIDB, respectively. The total drainage areas for LAKEDB and DIDB were 6.79 and $2.67 \mathrm{~km}^{2}$, respectively, which give the DARF values [48]. Similarly, the SC basin with a DARF of 0.908 for a drainage area of $11.27 \mathrm{~km}^{2}$ was used for the baseline scenario analysis of JP. For all three elements, along with the model from the baseline scenarios, an SC basin with a DARF of 0.875 for a drainage area of $21 \mathrm{~km}^{2}$ was used to determine the maximum values of modeling outputs, using two climate change scenarios.

For hydrological modeling, the inputs for the detention basin in the HEC-HMS model were the elevation storage functions and the storage discharge. Inflow-diversion functions were assigned as inputs for the diversion components. During the simulation with projected climate scenario of three detention basins and 10 diversion model components, the maximum values specified as inputs were exceeded. For all the components of interest, the function inputs were not exceeded. To complete simulation, the higher possible values were assigned for the exceeded functions. The assigned values were estimated using a linear extrapolation with the last two paired specified values.

The HEC-HMS model outputs for all the three scenarios are graphically presented in the Figures 4-6. The graphs in Figure 4a,b,d represent the direct outputs, inflow, discharge, and storage. Figure $4 \mathrm{c}$ shows the change in elevation with respect to time for all the three scenarios considered for LAKEDB. 


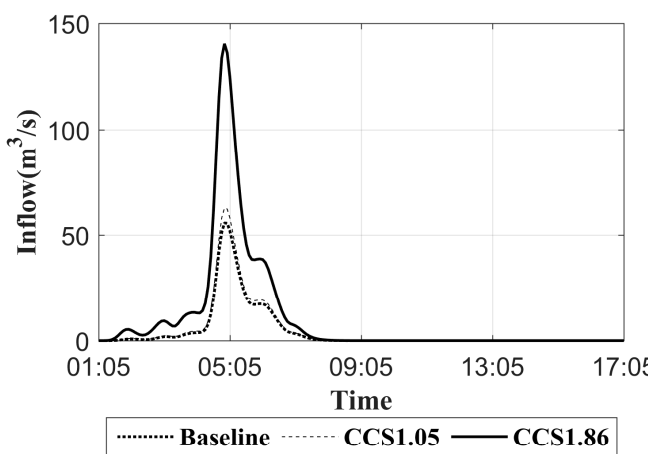

(a) Inflow-LAKEDB

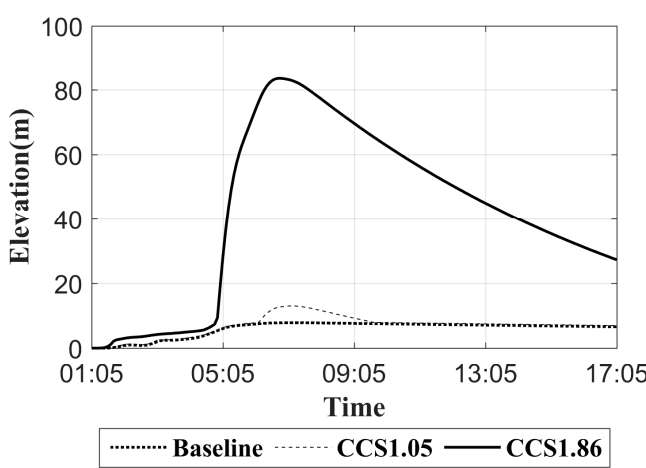

(c) Change in Elevation-LAKEDB

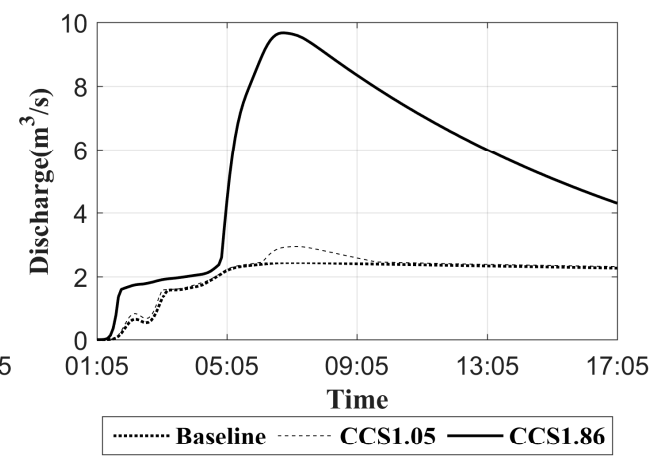

(b) Discharge-LAKEDB

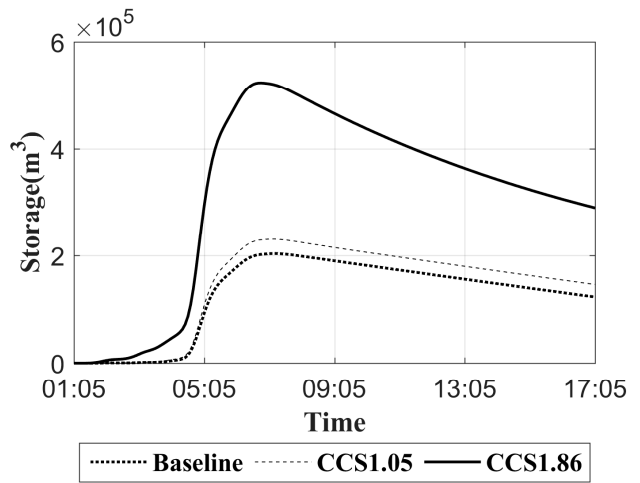

(d) Storage-LAKEDB

Figure 4. Time series plot of inflow, discharge, change in elevation, and storage from HEC-HMS outputs for the Lake Detention Basin (LAKEDB).

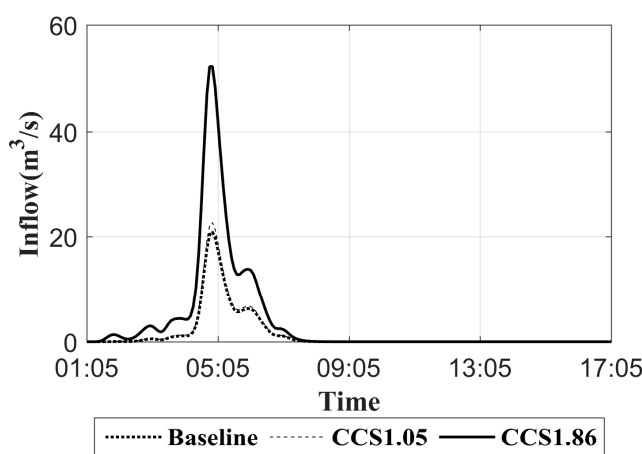

(a) Inflow-DIDB

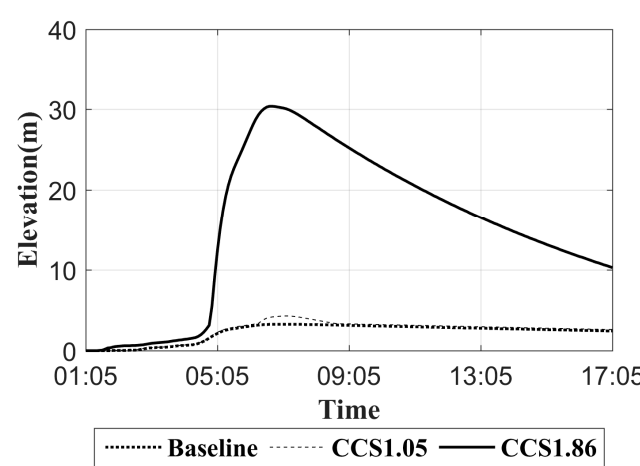

(c) Change in Elevation-DIDB

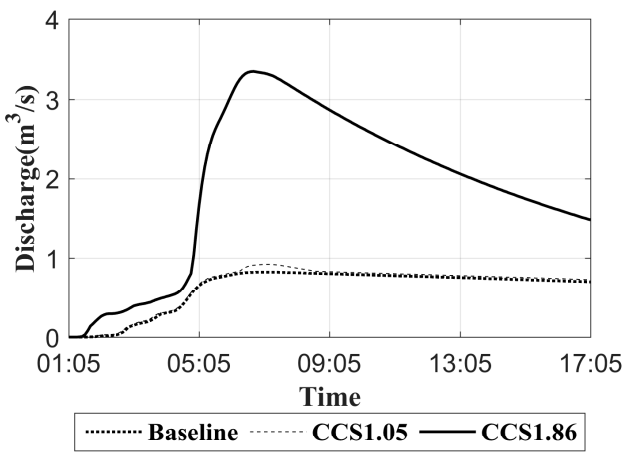

(b) Discharge-DIDB

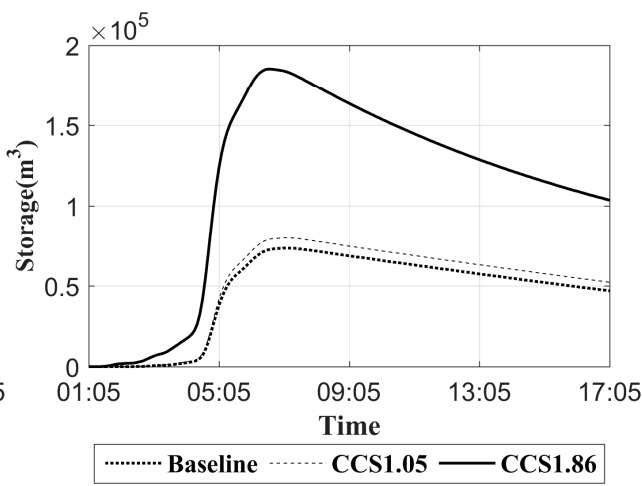

(d) Storage-DIDB

Figure 5. Time series plot of inflow, discharge, change in elevation, and storage from HEC-HMS outputs for the Desert Inn Detention Basin (DIDB). 


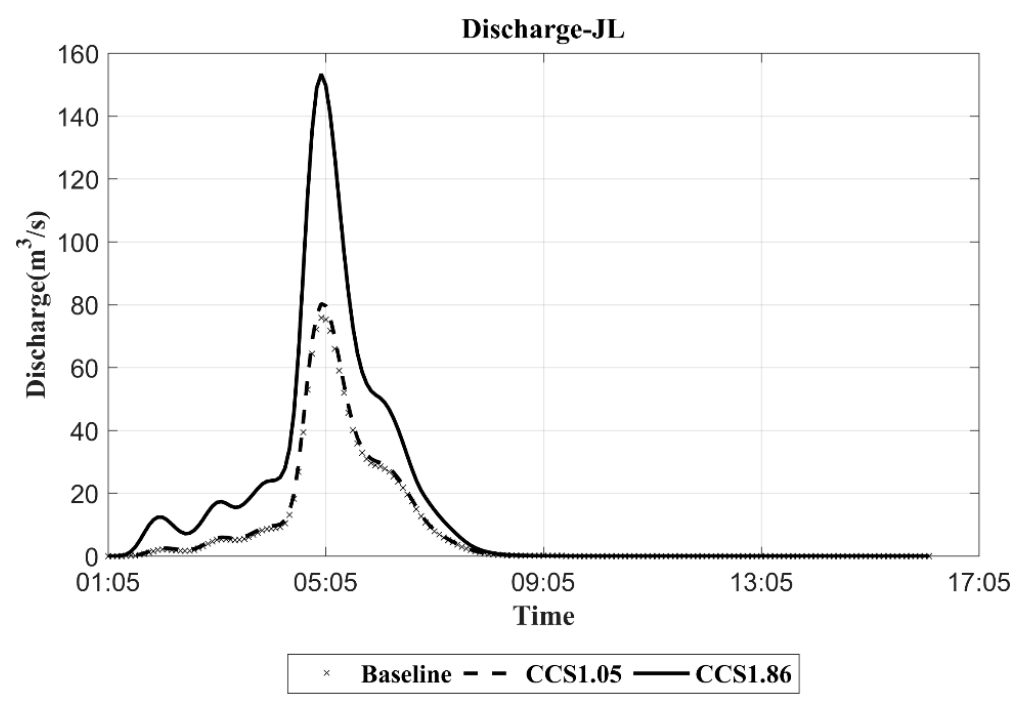

Figure 6. Time series plot of discharge at the junction point (JP) from the hydrological modeling.

The outputs for the baseline scenario were from the base model with a DARF of 0.925. However, the highest maximum outputs for the two climate scenarios, CCS 1.05 and CCS 1.86, were observed from the base model basin with a DARF of 0.95 . The maximum discharge was observed at 4:55 for all the three combinations since all the conditions had the same base model basin. However, the three other hydrologic parameters that were calculated-storage, change in elevation, and outflow-were observed at different times for each scenario. For the baseline scenario, the maximum value of these three parameters were observed at 7:15 am; 7:10 am, and 6:50 am were the observed peak times for other two scenarios, CCS 1.05 and CCS 1.86. The differences were expected because at different inflows for a detention basin, the diversion scenarios were different.

Figure 5a-d represent the HEC-HMS output for DIDB. The graphs in Figure 5a,b,d represent the direct outputs, inflow, discharge, and storage for DIDB; the change in elevation is shown in Figure 5c. The outputs for the baseline and the highest maximum outputs for both climate scenarios are observed from the base model with DARF 0.95. Similar to LAKEDB, the maximum discharge was observed at 4:55 am for all three combinations. The peak times for all other three hydrological parameters were observed at 7:10 am for the baseline and CCS 1.05 scenarios, and at 6:45 am for the CCS 1.86 scenario.

Figure 6 represents the hydrologic modeling output, discharge for JP. Consistent with the basin considered during the design, the SC basin produced the highest maximum discharge for the JP. Maximum discharges for all three scenarios considered were witnessed at the same time, at 5:00 am. The flow duration curve for all the scenarios showed the same pattern of flow; this is understandable since all are observed in the same SC basin model. Simulation results for the baseline hydrological model for all three components were close to the design values for inflow, elevation, and discharge. This illustrates that the HEC-HMS model is simulating the desired result. The slight difference is reasonable since the design values were taken from HEC-1.

\section{Discussion}

The 100yr-6hr historic and projected design depths that were calculated varied substantially from each NARCCAP model combination (refer to Table 2). The NARCCAP data resulted from different combinations of RCM and GCM models, and the spatial resolution used by all the RCMs differ only slightly from each other. However, the formulations and parametrization methods used by the RCMs vary greatly from each other [67]. These RCMs are driven by the four GCMs that again differ from each other with regard to formulations and parametrizations. The climate scenario was considered by implementing multiple sets of climate models, as recommended by Flower et al. [25]. In each combination of climate model datasets, various surrounding homogeneous grids were taken for the regional analysis in order to calculate $100 \mathrm{yr}-6 \mathrm{hr}$ depths. The analysis using homogenous grids 
increases the sample size and decreases an uncertainty to fit probability distribution. This type of regional analysis can be implemented for the low-frequency rainfall depths, using the gridded data.

In assessing the NARCCAP data, the 100yr-6hr historic depths that were greater than 100yr-6hr NARR historic depths were eliminated. A similar analysis performed by Forsee et al. [23], for the Pitman watershed of Las Vegas Valley, also eliminated the two NARCCAP datasets that are eliminated in this study. The difference between the current study compared to the previous work by Forsee et al. [23] is that the current study used all 13 combinations of climate data compared to using only 5 sets of climate data. The spatial resolution of NARCCAP datasets are lower than that of NARR data; it is anticipated that the average storm depths from lower resolution datasets would be less than that from higher resolution datasets. In the gridded climate model data, the depth for each grid is assigned with an average area basis. The NARCCAP data has a spatial resolution of $50 \mathrm{~km}$, whereas NARR data has a $32 \mathrm{~km}$ spatial resolution. The depth in the gridded climate data was determined by dividing the total rainfall depth by the area of the grid. The 100yr-6hr NOAA Atlas 14 centroidal $\left(36.09^{\circ} \mathrm{N}, 115.36^{\circ} \mathrm{W}\right)$ depth of Flamingo and Tropicana watershed is $5.7 \mathrm{~cm}$, and two of the eliminated NARCCAP depths were even greater than atlas depth [58].

DCFs used to assess climate change varied from each model combination, since each model has different estimations for historic and future depths. The use of the delta change method was simple and straightforward, eliminating tedious and complex downscaling methods. Downscaling methods, which transpose high-resolution climate model data to the watershed level, demand separate sets of complicated methods. The practice of complex downscaling methods makes the design of drainage more inappropriate by underlying assumption [12]. DCM was used previously by other studies, such as Flower et al. [25], Semadeni-Davies et al. [12] to assess the effects of climate change. Agreeing with this study's finding, Acharya et al. [68] also found an increase in the future design storms for the Flamingo and Tropicana watershed. Acharya et al. [68] performed the analysis using the average monthly precipitation from Coupled Model Intercomparison Project Phase 3 with best-fitted extreme value method. In the current analysis, one of the combinations estimated the delta change factor to be less than 1; this means that the projected climate scenario would be less severe than it is currently. Nevertheless, this factor was not considered for further study since the assessment of NARR depths already eliminated these values.

In the HEC-HMS hydrological modeling, baseline simulation results were very close to the design values, inflow, elevation, and discharge of the considered stormwater components. This illustrates that the HEC-HMS model simulated the desired result. A slight difference is reasonable since the design values were taken from HEC-1 [50]. Hydrological simulation for all three scenarios showed that the current design of most of the drainage facilities would be inadequate, even in the low future climate projection (CCS 1.05). The maximum climate projection, CCS 1.86, exceeded the capacity of all the drainage facilities and the detention basins. For the hydrological parameters under consideration of the three stormwater components selected for the Flamingo and Tropicana watershed, the minimum projected climate scenario (CCS 1.05) showed the changing factors from 1.06 to 1.36; meanwhile, the maximum projected climate scenario (CCS 1.86) showed the changing factors from 2.03 to 10.10.

\section{Conclusions}

This study was carried out in two phases: statistical analysis and hydrological analysis. Statistical analysis was conducted by using the GEV distribution and L-moments; an existing HEC-HMS was used for the hydrological analysis. At first, the 100yr-6hr design depths (historical and projected) were calculated for all the NARCCAP climate model datasets. The historical 100yr-6hr depth from the NARR dataset was used to assess the performance of NARCCAP climate models. The DCFs from all the selected NARCCAP datasets were calculated, and extreme values were taken for hydrological modeling. HEC-HMS was implemented for the hydrological modeling to assess effects of climate change on existing stormwater systems. The analysis of the present stormwater facilities of the Flamingo and Tropicana watershed showed that these facilities are unable to withhold the flows resulting from the projected climate scenario. The effects of climate change are already taking place, 
and this watershed is facing flooding every year. The exceedance of design values even for less severe projected climate scenarios as well as current yearly flooding of the region warrants an update for the existing stormwater facilities in this location. The updates could be increasing the storage capacity of existing stormwater facilities or implementation of green structures such as rainwater harvesting and green roofs. Trade-offs among management strategies need to be analyzed for the selection of these options.

This study demonstrated a robust and simple method that accounts the effects of climate change on the urban stormwater infrastructure design. There is an uncertainty in the future climate scenario that warrants considering a range of the probable future scenarios during the planning process. Climate change is anticipated to change the pattern, intensity, and frequency of extreme rainfall events. Existing drainage infrastructures are designed based on a constant hydrologic scenario with respect to time, which excludes the changing scenario with regard to climate. The current assumptions in the design of stormwater facilities are invalidated by recent studies on climate change. The results of this study can be helpful to design engineers, water managers, policy makers, and decision makers to include the climate change effects in the design of stormwater facilities.

Moreover, anthropogenic changes, urbanization, and deforestation in the watershed have amplified the effects of flooding. The consequences of flooding are devastating, and cause long-term as well as short-term effects. The peak flow, which is the main design parameter of a drainage system, is expected to increase due to climate change over its service life. The collective effects of projected climate change on an urban stormwater system are amplified by the fact that the service life of urban drainage infrastructure is much longer. The infrastructure should be designed with the sufficient capacity to handle flows during its lifetime rather than for requirements for present-day flow. In the near future, the present capacity of most urban drainage systems is expected to surpass their capacities. A method similar to what presented in this study could become a useful tool, and could be implemented to tackle the effects of climate change in the coming years.

Acknowledgments: The authors would like to thank the North American Regional Climate Change Assessment Program (NARCCAP) and National Centers for Environmental Prediction, NOAA Physical Science Division, Boulder, Colorado for providing the data used in this paper. The authors would also like to thank the Clark County Regional Flood Control District (CCRFCD) in Las Vegas, Nevada for giving access to the hydrological models and documentation. The authors are grateful to Office of Vice Chancellor at SIU Carbondale for providing research support. The authors would like to thank two anonymous reviewers for providing valuable comments that helped in improving the overall quality of the manuscript.

Author Contributions: Ajay Kalra and Sajjad Ahmad designed the research idea and the results are prepared by Ranjeet Thakali. All the authors analyzed the results and wrote the paper together.

Conflicts of Interest: The authors declare no conflict of interest

\section{Abbreviations}

The following abbreviations are used in this manuscript:

GCM Global Climate Model

RCM Regional Climate Model

CCRFCD Clark County Regional Flood Control District

NARCCAP North American Regional Climate Change Assessment Program

NARR North American Regional Reanalysis

GEV Generalized Extreme Value

\section{References}

1. Solomon, S.; Qin, D.; Manning, M.; Chen, Z.; Marquis, M.; Averyt, K.B.; Tignor, M.; Miller, H.L. Climate Change 2007-The Physical Science Basis: Contribution of Working Group I to the Fourth Assessment Report of the IPCC; Cambridge University Press: Cambridge, UK, 2007; Volume 4.

2. Christensen, J.H.; Hewitson, B.; Busuioc, A.; Chen, A.; Gao, X.; Held, R.; Jones, R.; Kolli, R.K.; Kwon, W.; Laprise, R. Regional climate projections. In Climate Change, 2007: The Physical Science Basis. Contribution of Working Group I to the Fourth Assessment Report of the Intergovernmental Panel on Climate Change; Cambridge University Press: Cambridge, UK, 2007; Chapter 11; pp. 847-940. 
3. Sagarika, S.; Kalra, A.; Ahmad, S. Interconnections between oceanic-atmospheric indices and variability in the US streamflow. J. Hydrol. 2015, 525, 724-736. [CrossRef]

4. Sagarika, S.; Kalra, A.; Ahmad, S. Pacific ocean SST and Z500 climate variability and western US seasonal streamflow. Int. J. Climatol. 2015, 36, 1515-1533. [CrossRef]

5. Pathak, P.; Kalra, A.; Ahmad, S. Temperature and precipitation changes in the midwestern united states: Implications for water management. Int. J. Water Resour. Dev. 2016. [CrossRef]

6. Tamaddun, K.; Kalra, A.; Ahmad, S. Identification of streamflow changes across the continental United States using variable record lengths. Hydrology 2016, 3, 24. [CrossRef]

7. Olsson, J.; Berggren, K.; Olofsson, M.; Viklander, M. Applying climate model precipitation scenarios for urban hydrological assessment: A case study in Kalmar city, Sweden. Atmos. Res. 2009, 92, 364-375. [CrossRef]

8. $\quad$ Easterling, D.R.; Evans, J.; Groisman, P.Y.; Karl, T.; Kunkel, K.E.; Ambenje, P. Observed variability and trends in extreme climate events: A brief review. Bull. Am. Meteorol. Soc. 2000, 81, 417-425. [CrossRef]

9. Sagarika, S.; Kalra, A.; Ahmad, S. Evaluating the effect of persistence on long-term trends and analyzing step changes in streamflows of the continental United States. J. Hydrol. 2014, 517, 36-53. [CrossRef]

10. Diodato, N.; Bellocchi, G.; Romano, N.; Chirico, G.B. How the aggressiveness of rainfalls in the Mediterranean lands is enhanced by climate change. Clim. Chang. 2011, 108, 591-599. [CrossRef]

11. Konrad, C.P. Effects of Urban Development on Floods; US Department of the Interior: Washington, DC, USA, 2003; US Geological Survey Fact Sheet FS-076-03.

12. Semadeni-Davies, A.; Hernebring, C.; Svensson, G.; Gustafsson, L.-G. The impacts of climate change and urbanization on drainage in Helsingborg, Sweden: Suburban stormwater. J. Hydrol. 2008, 350, 114-125. [CrossRef]

13. Obeysekera, J.; Salas, J.D. Quantifying the uncertainty of design floods under nonstationary conditions. J. Hydrol. Eng. 2013, 19, 1438-1446. [CrossRef]

14. Gilroy, K.L.; McCuen, R.H. A nonstationary flood frequency analysis method to adjust for future climate change and urbanization. J. Hydrol. 2012, 414, 40-48. [CrossRef]

15. Rosenberg, E.A.; Keys, P.W.; Booth, D.B.; Hartley, D.; Burkey, J.; Steinemann, A.C.; Lettenmaier, D.P. Precipitation extremes and the impacts of climate change on stormwater infrastructure in Washington state. Clim. Chang. 2010, 102, 319-349. [CrossRef]

16. Guo, Y. Updating rainfall idf relationships to maintain urban drainage design standards. J. Hydrol. Eng. 2006, 11, 506-509. [CrossRef]

17. Carrier, C.A.; Kalra, A.; Ahmad, S. Long-range precipitation forecasts using paleoclimate reconstructions in the Western United States. J. Mt. Sci. 2016, 13, 614-632. [CrossRef]

18. Pathak, P.; Kalra, A.; Ahmad, S.; Bernardez, M. Wavelet-aided analysis to estimate seasonal variability and dominant periodicities in temperature, precipitation, and streamflow in the Midwestern United States. Water Resour. Manag. 2016. [CrossRef]

19. Tamaddun, K.A.; Kalra, A.; Ahmad, S. Wavelet analysis of Western US streamflow with ENSO and PDO. J. Water Clim. Chang. 2016. [CrossRef]

20. Mailhot, A.; Duchesne, S. Design criteria of urban drainage infrastructures under climate change. J. Water Resour. Plan. Manag. 2010, 136, 201-208. [CrossRef]

21. Milly, P.; Julio, B.; Malin, F.; Robert, M.; Zbigniew, W.; Dennis, P.; Ronald, J. Stationarity is dead. Ground Water News Views 2008, 4, 6-8.

22. Wernstedt, K.; Carlet, F. Climate change, urban development, and storm water: Perspectives from the field. J. Water Resour. Plan. Manag. 2014, 140, 543-552. [CrossRef]

23. Forsee, W.J.; Ahmad, S. Evaluating urban storm-water infrastructure design in response to projected climate change. J. Hydrol. Eng. 2011, 16, 865-873. [CrossRef]

24. Hagemann, S.; Chen, C.; Clark, D.; Folwell, S.; Gosling, S.N.; Haddeland, I.; Hannasaki, N.; Heinke, J.; Ludwig, F.; Voss, F. Climate change impact on available water resources obtained using multiple global climate and hydrology models. Earth Syst. Dyn. 2013, 4, 129-144. [CrossRef]

25. Fowler, H.; Blenkinsop, S.; Tebaldi, C. Linking climate change modelling to impacts studies: Recent advances in downscaling techniques for hydrological modelling. Int. J. Climatol. 2007, 27, 1547-1578. [CrossRef]

26. Mearns, L.; Sain, S.; Leung, L.; Bukovsky, M.; McGinnis, S.; Biner, S.; Caya, D.; Arritt, R.; Gutowski, W.; Takle, E. Climate change projections of the North American regional climate change assessment program (NARCCAP). Clim. Chang. 2013, 120, 965-975. [CrossRef] 
27. Christensen, J.H.; Boberg, F.; Christensen, O.B.; Lucas-Picher, P. On the need for bias correction of regional climate change projections of temperature and precipitation. Geophys. Res. Lett. 2008. [CrossRef]

28. Mearns, L.; Lettenmaier, D.; McGinnis, S. Uses of results of regional climate model experiments for impacts and adaptation studies: The example of NARCCAP. Curr. Clim. Chang. Rep. 2015, 1, 1-9. [CrossRef]

29. Diaz-Nieto, J.; Wilby, R.L. A comparison of statistical downscaling and climate change factor methods: Impacts on low flows in the River Thames, United Kingdom. Clim. Chang. 2005, 69, 245-268. [CrossRef]

30. Mailhot, A.; Duchesne, S.; Caya, D.; Talbot, G. Assessment of future change in intensity-duration-frequency (IDF) curves for Southern Quebec using the Canadian regional climate model (CRCM). J. Hydrol. 2007, 347, 197-210. [CrossRef]

31. Zoppou, C. Review of urban storm water models. Environ. Model. Softw. 2001, 16, 195-231. [CrossRef]

32. Gaber, N.; Foley, G.; Pascual, P.; Stiber, N.; Sunderland, E.; Cope, B.; Saleem, Z. Guidance on the Development, Evaluation, and Application of Environmental Models; US Environmental Protection Agency: Washington, DC, USA, March 2009.

33. Elliott, A.; Trowsdale, S. A review of models for low impact urban stormwater drainage. Environ. Model. Softw. 2007, 22, 394-405. [CrossRef]

34. Salvadore, E.; Bronders, J.; Batelaan, O. Hydrological modelling of urbanized catchments: A review and future directions. J. Hydrol. 2015, 529, 62-81. [CrossRef]

35. Grum, M.; Jorgensen, A.; Johansen, R.; Linde, J. The effect of climate change on urban drainage: An evaluation based on regional climate model simulations. Water Sci. Technol. 2006, 54, 9-15. [CrossRef] [PubMed]

36. He, J.; Valeo, C.; Bouchart, F. Enhancing urban infrastructure investment planning practices for a changing climate. Water Sci. Technol. 2006, 53, 13-20. [CrossRef] [PubMed]

37. Brown, C. The end of reliability. J. Water Resour. Plan. Manag. 2010, 136, 143-145. [CrossRef]

38. Jardine, A.; Merideth, R.; Black, M.; LeRoy, S. Assessment of Climate Change in the Southwest United States: A Report Prepared for the National Climate Assessment; Island Press: Washington, DC, USA, 2013.

39. Levick, L.R.; Goodrich, D.C.; Hernandez, M.; Fonseca, J.; Semmens, D.J.; Stromberg, J.C.; Tluczek, M.; Leidy, R.A.; Scianni, M.; Guertin, D.P. The Ecological and Hydrological Significance of Ephemeral and Intermittent Streams in the Arid and Semi-Arid American Southwest; US Environmental Protection Agency: Washington, DC, USA, November 2008.

40. Reilly, J.A.; Piechota, T.C. Actual storm events outperform synthetic design storms. A review of SCS curve number applicability. In Proceedings of the World Water and Environmental Resources Congress, Anchorage, AK, USA, 15-19 May 2005; American Society of Civil Engineers: Reston, VA, USA, 2005; pp. 1-13. Available online: http://www.egr.unlv.edu/ piechota/proceedings/reilly-piechota-ewri-2005.pdf (assessed on 5 October 2016).

41. A Nevada Division of Water Resources Cooperative Technical Partner Project (NDWRCTPP), Nevada Flood Risk Portfolio: Flood Hazards and Flood Risk in Nevada's Watersheds. 2013. Available online: http: / / water.nv.gov/programs/flood/hazards.pdf (assessed on 5 October 2016).

42. Clark County Regional Flood Control District (CCRFCD). Regional Flood Control District Annual Report, Clark County, Nevada, 2014-2015; CCRFCD: Clark County, NV, USA, 2015; Available online: http:/ / gustfront.ccrfcd. org/pdf_arch1/public\%20information/annual\%20reports/Annual\%20Report\%20-\%2014-15.pdf (assessed on 5 October 2016).

43. Mearns, L.; Gutowski, W.; Jones, R.; Leung, L.; McGinnis, S.; Nunes, A.; Qian, Y. The North American Regional Climate Change Assessment Program Dataset; National Center for Atmospheric Research Earth System Grid Data Portal: Boulder, CO, USA, 2007; Available online: https:/ /www.earthsystemgrid.org/project/narccap. html (assessed on 5 October 2016).

44. Mesinger, F.; DiMego, G.; Kalnay, E.; Mitchell, K.; Shafran, P.C.; Ebisuzaki, W.; Jovic, D.; Woollen, J.; Rogers, E.; Berbery, E.H. North American regional reanalysis. Bull. Am. Meteorol. Soc. 2006, 87, 343-360. [CrossRef]

45. Mesinger, F.; DiMego, G.; Kalnay, E.; Shafran, P.; Ebisuzaki, W.; Jovic, D.; Woollen, J.; Mitchell, K.; Rogers, E.; Ek, M. NCEP North American Regional Reanalysis. In Proceedings of the 15th Symposium on Climate Change and Global Variations, 84th Conference of the AMS, Seattle, WA, USA, 11-15 January 2004.

46. Kennedy, A.D.; Dong, X.; Xi, B.; Xie, S.; Zhang, Y.; Chen, J. A comparison of MERRA and NARR reanalyses with the DOE ARM SGP data. J. Clim. 2011, 24, 4541-4557. [CrossRef] 
47. Clark County Regional Flood Control District (CCRFCD). 2013 Las Vegas Valley Flood Control Master Plan Update; CCRFCD: Las Vegas, NV, USA, 2013.

48. Clark County Regional Flood Control District (CCRFCD). Hydrologic Criteria and Drainage Design Manual; CCRFCD: Las Vegas, NV, USA, 1999.

49. Miller, J.F.; Frederick, R.H.; Tracey, R.J. Precipitation-frequency Atlas of the Western United States; US Department of Commerce, National Oceanic \& Atmospheric Administration: Washington, DC, USA, 1973.

50. Clark County Regional Flood Control District (CCRFCD). 2008 Las Vegas Valley Flood Control Master Plan Update, Volume I and II; CCRFCD: Las Vegas, NV, USA, 2008.

51. Hosking, J.R.M.; Wallis, J.R. Regional Frequency Analysis: An Approach Based on L-Moments; Cambridge University Press: Cambridge, UK, 1997; p. 224.

52. Kendon, E.J.; Rowell, D.P.; Jones, R.G.; Buonomo, E. Robustness of future changes in local precipitation extremes. J. Clim. 2008, 21, 4280-4297. [CrossRef]

53. Burn, D.H. Evaluation of regional flood frequency analysis with a region of influence approach. Water Resour. Res. 1990, 26, 2257-2265. [CrossRef]

54. Castellarin, A.; Galeati, G.; Brandimarte, L.; Montanari, A.; Brath, A. Regional flow-duration curves: Reliability for ungauged basins. Adv. Water Resour. 2004, 27, 953-965. [CrossRef]

55. Norbiato, D.; Borga, M.; Sangati, M.; Zanon, F. Regional frequency analysis of extreme precipitation in the eastern italian alps and the august 29, 2003 flash flood. J. Hydrol. 2007, 345, 149-166. [CrossRef]

56. Fowler, H.; Wilby, R. Detecting changes in seasonal precipitation extremes using regional climate model projections: Implications for managing fluvial flood risk. Water Resour. Res. 2010, 46. [CrossRef]

57. Institute of Hydrology. Flood Estimation Handbook; Institute of Hydrology: Wallingford, UK, 1999.

58. Bonnin, G.M.; Martin, D.; Lin, B.; Parzybok, T.; Yekta, M.; Riley, D. Precipitation-17 Frequency Atlas of the United States, NOAA Atlas 14, NOAA; National Weather Service: Silver Spring, MD, USA, 2011; Volume 1.

59. Kharin, V.V.; Zwiers, F.W. Changes in the extremes in an ensemble of transient climate simulations with a coupled atmosphere-ocean GCM. J. Clim. 2000, 13, 3760-3788. [CrossRef]

60. Delgado, J.M.; Apel, H.; Merz, B. Flood trends and variability in the Mekong River. Hydrol. Earth Syst. Sci. 2010, 14, 407-418. [CrossRef]

61. Gül, G.O.; Aşıkoğlu, Ö.L.; Gül, A.; Gülçem Yaşoğlu, F.; Benzeden, E. Nonstationarity in flood time series. J. Hydrol. Eng. 2013, 19, 1349-1360. [CrossRef]

62. Katz, R.W.; Parlange, M.B.; Naveau, P. Statistics of extremes in hydrology. Adv. Water Resour. 2002, 25, 1287-1304. [CrossRef]

63. Prosdocimi, I.; Kjeldsen, T.; Miller, J. Detection and attribution of urbanization effect on flood extremes using nonstationary flood-frequency models. Water Resour. Res. 2015, 51, 4244-4262. [CrossRef] [PubMed]

64. Salas, J.D.; Obeysekera, J. Revisiting the concepts of return period and risk for nonstationary hydrologic extreme events. J. Hydrol. Eng. 2014, 19, 554-568. [CrossRef]

65. Las Vegas Review-Journal. Las Vegas, NN, USA, 2016. Available online: http:/ /www.reviewjournal.com/ weather/4-rescued-during-record-breaking-rainfall-las-vegas-valley-photos (assessed on 5 October 2016).

66. PressReader Online Journal. British Columbia, Canada, 2016. Available online: http:/ /www.pressreader. com/usa/las-vegas-review-journal-sunday/20160410/282067686091968 (assessed on 5 October 2016).

67. Wehner, M.F. Very extreme seasonal precipitation in the narccap ensemble: Model performance and projections. Clim. Dyn. 2013, 40, 59-80. [CrossRef]

68. Acharya, A.; Lamb, K.; Piechota, T.C. Impacts of climate change on extreme precipitation events over Flamingo Tropicana Watershed. J. Am. Water Resour. Assoc. 2013, 49, 359-370. [CrossRef]

(c) 2016 by the authors; licensee MDPI, Basel, Switzerland. This article is an open access article distributed under the terms and conditions of the Creative Commons Attribution (CC-BY) license (http://creativecommons.org/licenses/by/4.0/). 